\title{
Liquid Acquisition Device Testing with Sub-Cooled Liquid Oxygen
}

\author{
John M. Jurns* \\ ASRC Aerospace Corp., Cleveland, $\mathrm{OH}, 44135$ \\ John B. McQuillen ${ }^{\dagger}$ \\ NASA Glenn Research Center, Cleveland, OH, 44135
}

\begin{abstract}
When transferring propellant in space, it is most efficient to transfer single phase liquid from a propellant tank to an engine. In earth's gravity field or under acceleration, propellant transfer is fairly simple. However, in low gravity, withdrawing single-phase fluid becomes a challenge. A variety of propellant management devices (PMD) are used to ensure single-phase flow. One type of PMD, a liquid acquisition device (LAD) takes advantage of capillary flow and surface tension to acquire liquid. Previous experimental test programs conducted at NASA have collected LAD data for a number of cryogenic fluids, including: liquid nitrogen $\left(\mathrm{LN}_{2}\right)$, liquid oxygen (LOX), liquid hydrogen $\left(\mathrm{LH}_{2}\right)$, and liquid methane $\left(\mathrm{LCH}_{4}\right)$. The present work reports on additional testing with sub-cooled LOX as part of NASA's continuing cryogenic LAD development program. Test results extend the range of LOX fluid conditions examined, and provide insight into factors affecting predicting LAD bubble point pressures.
\end{abstract}

\section{Nomenclature}

$\begin{array}{ll}\mathrm{D}_{\mathrm{p}} & \text { Pore diameter (inch) } \\ \Delta \mathrm{P}_{\mathrm{BP}} & \left.\text { Bubble point pressure (inch } \mathrm{H}_{2} \mathrm{O}\right) \\ \rho & \text { Fluid density }\left(\mathrm{lb} / \mathrm{ft}^{3}\right) \\ \sigma & \text { Surface tension }(\mathrm{Lb} / \mathrm{in}) \\ v & \text { Kinematic viscosity }\left(\mathrm{ft}^{2} / \mathrm{sec}\right) \\ \theta_{\mathrm{c}} & \text { Fluid contact angle }(\text { degree })\end{array}$

\section{Introduction}

When transferring propellant in space, it is most efficient to transfer single phase liquid from a propellant tank to an engine. In earth's gravity field or under acceleration, propellant transfer is fairly simple. An anti-vortex baffle is installed over the tank outlet, and single-phase fluid is transferred by opening a valve at the bottom of the propellant tank. In low gravity, where fluid is not centered over the tank outlet, withdrawing only single-phase fluid becomes a challenge. A variety of propellant management devices (PMD) are used to ensure single-phase flow. One type of PMD, a liquid acquisition device (LAD) takes advantage of capillary flow and surface tension to acquire liquid. Capillary flow LADs have been well characterized for storable propellants (propellants that are liquids at room temperature) for in-space propulsion needs ${ }^{1}$.

Previous experimental test programs conducted at NASA Glenn Research Center and Marshall Space Flight Center have collected LAD data for a number of cryogenic fluids, including: liquid nitrogen $\left(\mathrm{LN}_{2}\right)$, liquid oxygen (LOX), liquid hydrogen $\left(\mathrm{LH}_{2}\right)$, and liquid methane $\left(\mathrm{LCH}_{4}\right)$. As part of NASA's continuing Cryogenic Fluid Management (CFM) development program. The present work reports on additional testing with LOX and isopropyl alcohol (IPA) to better understand the influence of subcooling on LAD performance.

\footnotetext{
${ }^{*}$ Research Engineer, Components \& Modeling Section, 21000 Brookpark Road//Mail Stop 500-ASRC, AIAA Member.

${ }^{\dagger}$ Aerospace Engineer, Fluid Physics and Transport Branch, 21000 Brookpark Road//Mail Stop 77-5, Non-Member.
} 
Capillary flows LADs have been well characterized for storable propellants. Over the past decade there has been an interest in extending the applications of LADs to cryogenic liquids. The screen channel capillary flow LAD, consisting of multiple channels located with in close proximity of the tank wall (typically $0.25 \mathrm{in}$ ), is of interest because of its ability to perform in a variety of gravitational environments. The portion of the channel facing the tank wall is covered with a tightly woven screen. Surface tension and wicking of the propellant trapped in the pores of the screen prevents the flow of vapor into the channel and ensures vapor free propellant delivery.

A number of screen weaves are suitable for use in LAD channels. The weave pattern, which refers to the type of over/under pattern used in manufacturing the screen, is an important parameter affecting the choice of screen; certain wire weaves produce much finer pore sizes than other weaves. The tightness of the weave (usually designated by the number of wires per inch in each direction) and the weave pattern also determine the geometry of the pores in the screen. The geometry (size) of the pore and the surface tension of the fluid trapped within the screen determine the bubble point of the screen. "Bubble point" is defined as the differential pressure across the screen that overcomes the surface tension of the liquid on the screen. A high bubble point (fine screen mesh) is desirable to ensure single phase (liquid) fluid delivery and good wicking of fluid into the screen pores. Fine mesh screens however, tend to produce a large pressure drop during outflow. The total pressure loss in the system must be less than the bubble point pressure to prevent vapor ingestion into a LAD channel.

\section{Liquid Oxygen Tests}

\section{Test Purpose/Objective}

Previous tests with $\mathrm{LCH}_{4}$ have indicated that the standard method ${ }^{2}$ for calculating bubble point shown in Eq. (1) appears to under-predict $\Delta P_{B P}$ for subcooled $\mathrm{LCH}_{4}$.

$$
\Delta P_{B P}=\frac{4 \sigma \cos \theta_{c}}{D_{p}}
$$

Here, $\sigma$ is the surface tension of the liquid and $\theta_{c}$ is the contact angle of the liquid on the screen material. For $\mathrm{LCH}_{4}, \theta_{c} \approx 0$ so $\cos \theta_{c}=1$ [Dodge ${ }^{2}$ ]. The effective pore diameter of the screen weave is $D_{P}$. Note that Kudlac and Jurns ${ }^{6}$ used the standard practice for determining the effective pore diameter for a particular screen which is to measure $\Delta P_{B P}$ with a special bubble-point apparatus using IPA as a reference liquid and calculating $D_{P}$ for the screen weave from Eq. (1). This value of $D_{P}$ is then used to compute the theoretical bubble-point pressure for the LAD screens used for these tests. The $D_{P}$ was determined to be 0.000873 inch $(0.0222 \mathrm{~mm})$ for the $200 \mathrm{X} 1400$ mesh screen and 0.000567 inch $(0.0144 \mathrm{~mm})$ for the $325 \mathrm{X} 2300$ mesh screen used in this test. Surface tension values for these tests were obtained from the NIST thermodynamic fluid property software program GASPAK ${ }^{3}$ The source in this program for surface tension properties is Sprow \& Prausnitz ${ }^{4}$. Surface tension values were chosen based on the temperature of the LOX near the screen interface. The screens used for these tests were the identical screens used by Kudlac and Jurns.

It has been previously posed that correlation between observed test data and predictions for $\mathrm{LCH}_{4}$ appeared to improve by considering additional terms in Eq. (1) and a closer examination of uncertainties in the fluid properties. A kinematic viscosity term was proposed ${ }^{7}$ to improve the correlation, and additional testing over a broader range of fluid conditions was desired. Test results reported here with subcooled LOX were performed to better understand how LAD performance is affected by these factors.

Additionally, Jurns, et al. examined the influence of the screen mesh variability ${ }^{7}$. That is, the LAD screen mesh is woven and minute variations in the weaving results in a non-uniform, non-circular pore diameter. Eliminating this variation may help better define the influence of other test parameters such as viscosity. To that end, several micro-machined orifices with varying geometries were procured and bubble point tested in IPA with the goal of better understanding the relationship between pore diameter and screen geometry.

\section{A. LAD Test Hardware}

Figure 1 shows a detail of the LAD screens used for these tests. The screen is a Dutch twill screen, where each shute wire travels over two warp wires before going under a warp wire. Figure 2 shows the cylindrical test article used

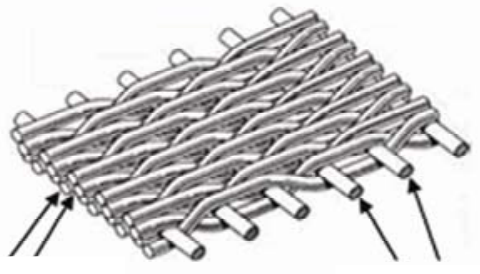

Shute Wires

Figure 1. Dutch Twill mesh screen showing weave pattern

American Institute of Aeronautics and Astronautics 
for bubble point testing installed in the test dewar. A screen sample is welded into the flanged top of the test article. The flanged design allows for rapid change out of various screen samples. A mirror aids in viewing the screen surface. Positioning the mirror over the screen surface provides both a side view and top view for a single camera to observe gas bubbles passing through the screen. Pressure transducers, external to a cryogenic test dewar, were connected to instrument taps on the test article and measured the differential pressure across the LAD screen as shown in Figure 3.

Screen size - The LAD screens used for these tests are welded to the top flange of the test article shown in Figure 2. The screen diameter is 2.5 inch $(6.25 \mathrm{~cm})$. The surface area exposed to the liquid is $4.91 \mathrm{in}^{2}\left(31.7 \mathrm{~cm}^{2}\right)$.

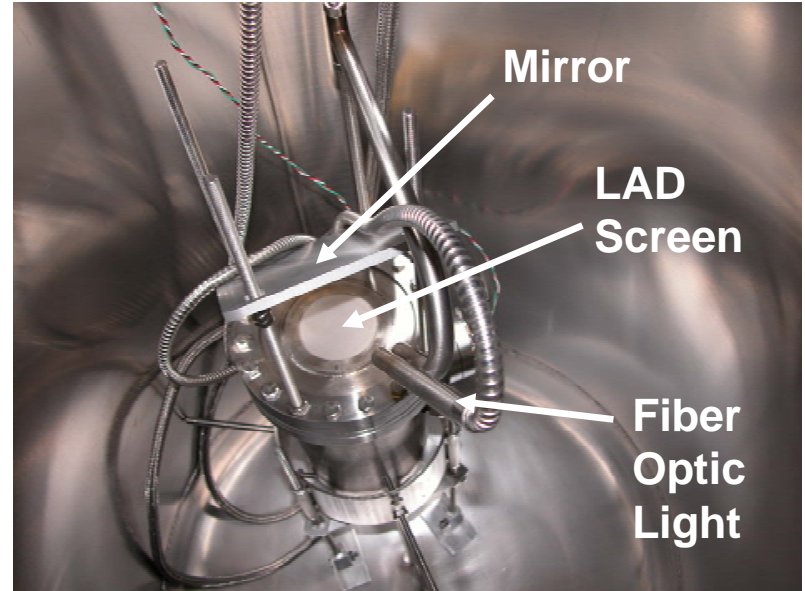

Figure 2. Test article installed inside cryogenic dewar.

\section{B. Test Facility}

CCL-7 is a small scale testing facility for concept and component testing 5 . In addition to component screening, the facility can perform propellant transfer, propellant conditioning (warming and sub-cooling), and vent flow tests. CCL-7 safely handles $1130 \mathrm{~L}$ (300 gallons) of $\mathrm{LN}_{2}$, and $230 \mathrm{~L}$ (60 gallons) of LOX. Gaseous helium $(\mathrm{GHe})$ and gaseous nitrogen $\left(\mathrm{GN}_{2}\right)$ are available on-site.

For this test program, the LAD hardware shown in Figure 2 was installed in one of the test facility dewars. Fluid supply and vent piping, and instrumentation lines pass through the lid of this dewar. The diameter of this dewar is 22 inch $(55.9 \mathrm{~cm})$. An instrument rake equipped with

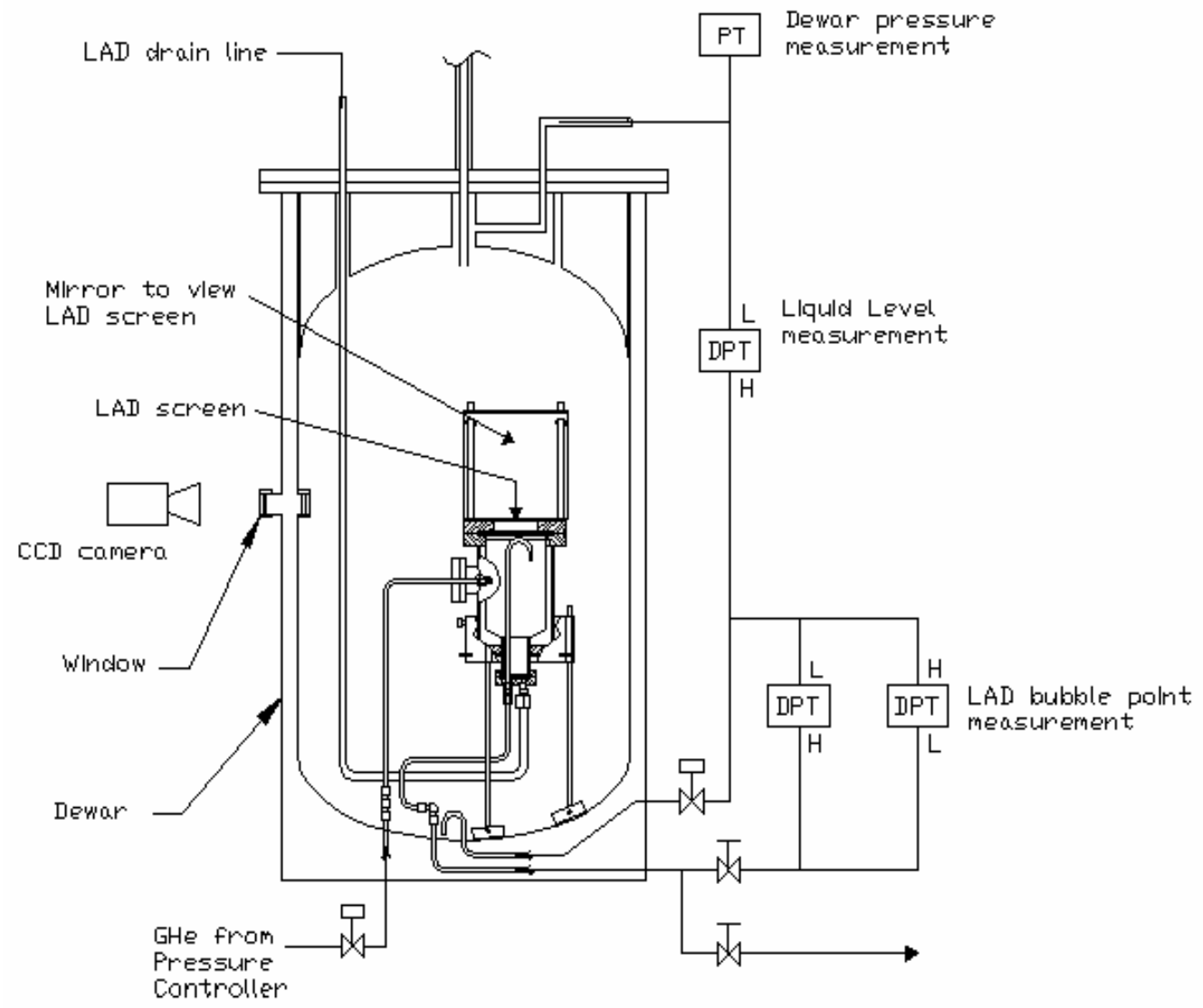

Figure 3. LAD test article installed inside test dewar showing instrumentation detail. 
silicon diodes provides temperature measurement and liquid level indication. The dewar is 42 inch $(106.7 \mathrm{~cm})$ deep, has an internal volume of $7.9 \mathrm{ft}^{3}(224 \mathrm{~L})$, and has a working pressure of $40 \mathrm{psia}(276 \mathrm{KPa})$. A window in the sidewall is located 22 inch $(55 \mathrm{~cm})$ from the bottom of the dewar.

LOX was transferred through facility piping into the test dewar. Tests were performed at three different LOX temperatures. LOX temperature above its normal boiling point was achieved by filling against a back pressure in the test dewar and allowing the LOX to warm to a higher temperature while filling. Maximum LOX temperature achieved for these tests was approximately 171 degree Rankine (95K). Fluid temperatures below normal boiling point (NBP) were achieved by flowing LOX through tubing immersed in a dewar filled with $\mathrm{LN}_{2}$. The LOX then

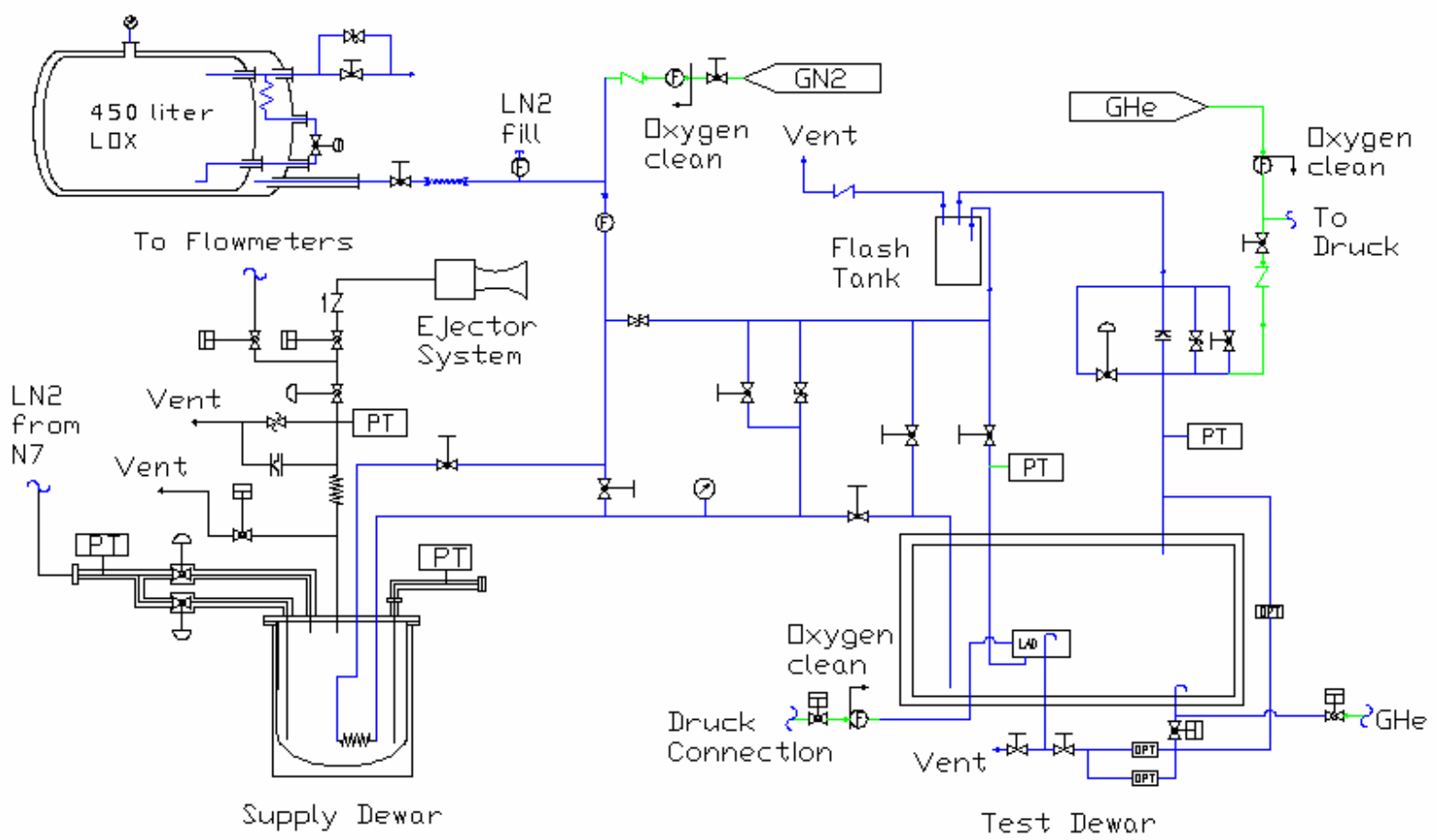

Figure 4. Schematic diagram of CCL-7 LOX LAD test

entered the test dewar. Colder temperatures were achieved by reducing pressure in the $\mathrm{LN}_{2}$ dewar ullage using the facility ejector system. Minimum LOX temperature achieved was about 152 degree Rankine (84.4K).

Instrumentation/Data Acquisition - CCL-7 utilizes a PC-based data collection system. Up to 320 channels of data can be collected at a nominal rate of $1 \mathrm{~Hz}$. Many of the facility channels are pre-configured for standard instruments including thermocouples, pressure transducers, and silicon diodes. A high accuracy ( $\pm 0.11 \%$ full scale) 0-30 inch $\mathrm{H}_{2} \mathrm{O}(0-7.47 \mathrm{KPa})$ pressure transducer measures differential pressure across the LAD screen. Interlocks, alarms and shutdowns protect the research hardware and facility.

Video - In order to determine the bubble point pressure, the LAD screen was observed during the test to determine the differential pressure at which bubbles broke through the screen. A digital video camera at test facility images the LAD screen through the view port on the side of the test dewar. The video signal is recorded in a digital format movie. Video data is time stamped and synchronized with the data collected for post test data processing.

\section{Test Results}

Comparison with historical data - Bubble point data has previously been reported for IPA by Kudlac and Jurns ${ }^{6}$, Cady $(1973)^{8}$ and $(1977)^{10}$, and Chato and Kudlac ${ }^{9}$; for $\mathrm{LH}_{2}$ by Cady $(1973)^{8}$, and Chato and Kudlac ${ }^{9}$; for $\mathrm{LN}_{2}$ by Kudlac and Jurns ${ }^{6}$, and Chato and Kudlac ${ }^{9}$; for LOX by Kudlac and $\mathrm{Jurns}^{6}$; and for $\mathrm{LCH}_{4}$ by Jurns, et al. ${ }^{7}$, and Jurns and McQuillen ${ }^{11}$. Cady (1977) ${ }^{10}$ reported bubble point values for $\mathrm{LH}_{2}$ based on liquid saturated at 50 psia (344.7 $\mathrm{KPa}$ ). Kudlac and Jurns ${ }^{6}$ reported bubble point predictions for $\mathrm{LO}_{2}$ and $\mathrm{LN}_{2}$ were based on saturated liquid at NBP. Chato and Kudlac ${ }^{9}$ did not report fluid conditions; however, a review of their test data indicated that $\mathrm{LN}_{2}$ temperature was 142.5 degree $\mathrm{R}(79.2 \mathrm{~K})$ and $\mathrm{LH}_{2}$ temperature was 39.6 degree $\mathrm{R}(21.9 \mathrm{~K})$. Jurns and McQuillen ${ }^{11}$ reported bubble points for $\mathrm{LCH}_{4}$ saturated at approximately 187 degree $\mathrm{R}(103.9 \mathrm{~K})$ and 203 degree $\mathrm{R}(112.8 \mathrm{~K})$. 
Using surface tension values for these conditions, predicted bubble point values were calculated using Eq. (1). Plots of predicted and measured bubble points versus surface tension for both 200 X 1400 and 325 X 2300 LAD screen are shown in Figure 4.

$\triangle P_{B P}$ Predictions based on surface tension - Equation (1) predicts bubble point reasonably well for NBP liquid. However, the $\mathrm{LCH}_{4}$ test data shows that Eq. (1) under-predicts the bubble point pressure for subcooled liquid ${ }^{11}$. In an attempt to improve the correlation for bubble point, an analysis by Gauglitz and Radke ${ }^{12}$ for bubbles traversing through constricted capillaries was used by Jurns et al. ${ }^{7}$, to propose adding a normalized kinematic viscosity term as shown in Eq. (2).

$$
\Delta P_{B P}=\frac{4 \sigma \cos \theta_{c}}{D_{p}}\left(\frac{v}{v_{N B P}}\right)^{1 / 3}
$$

These test data showed that including this normalized viscosity term is not appropriate, and that poor correlations between bubble point predictions and data may be better explained by other factors.

Table 1 lists test results for both LAD screens in LOX. Bubble point measured values are an average of all data taken for that condition. Bubble point predicted values are calculated from Eq (1). Surface tension values are taken from NIST data for saturated liquid at the LOX temperature measured closest to the LAD screen.

Table 1 - LOX LAD Bubble Point Summary

\begin{tabular}{|c|c|c|c|c|}
\hline $\begin{array}{c}\text { LOX Temp } \\
(\mathbf{R})\end{array}$ & $\begin{array}{c}\text { LOX } \\
\text { Condition }\end{array}$ & $\begin{array}{c}\text { Surface Tension } \\
(\mathbf{L b} / \mathbf{i n})\end{array}$ & $\begin{array}{c}\Delta \boldsymbol{P}_{\boldsymbol{B P}} \text { Measured } \\
\left(\text { Inch } \mathbf{H}_{\mathbf{2}} \mathbf{O}\right)\end{array}$ & $\begin{array}{c}\Delta \boldsymbol{P}_{\boldsymbol{B P}} \text { Predicted } \\
\left(\text { Inch } \mathbf{H}_{\mathbf{2}} \mathbf{O}\right)\end{array}$ \\
\hline \multicolumn{5}{|c|}{$\mathbf{2 0 0} \mathbf{X} \mathbf{1 4 0 0}$ mesh, $\mathbf{D}_{\mathbf{p}}=\mathbf{0 . 0 0 0 8 7}$ in } \\
\hline 154.1 & Cold & $8.07 \mathrm{E}-05$ & 12.22 & 10.24 \\
\hline 161.7 & NBP & $7.47 \mathrm{E}-05$ & 10.05 & 9.48 \\
\hline 169.3 & Warm & $6.88 \mathrm{E}-05$ & 9.19 & 8.73 \\
\hline \multicolumn{5}{|c|}{$\mathbf{3 2 5} \mathbf{X} \mathbf{2 3 0 0 ,} \mathbf{D}_{\mathbf{p}}=\mathbf{0 . 0 0 0 5 7}$ in } \\
\hline 155.5 & Cold & $7.96 \mathrm{E}-05$ & 18.23 & 15.57 \\
\hline 162.6 & NBP & $7.39 \mathrm{E}-05$ & 15.61 & 14.46 \\
\hline 169.9 & Warm & $6.83 \mathrm{E}-05$ & 13.93 & 13.35 \\
\hline 171.8 & Warm & $6.74 \mathrm{E}-05$ & 14.7 & 13.17 \\
\hline
\end{tabular}

Figure 5 shows test results and predictions for bubble point tests for the 200X1400 mesh LAD in LOX at the

Bubble Point vs surf tn, data \& predictions, 200X1400 LAD, LOX

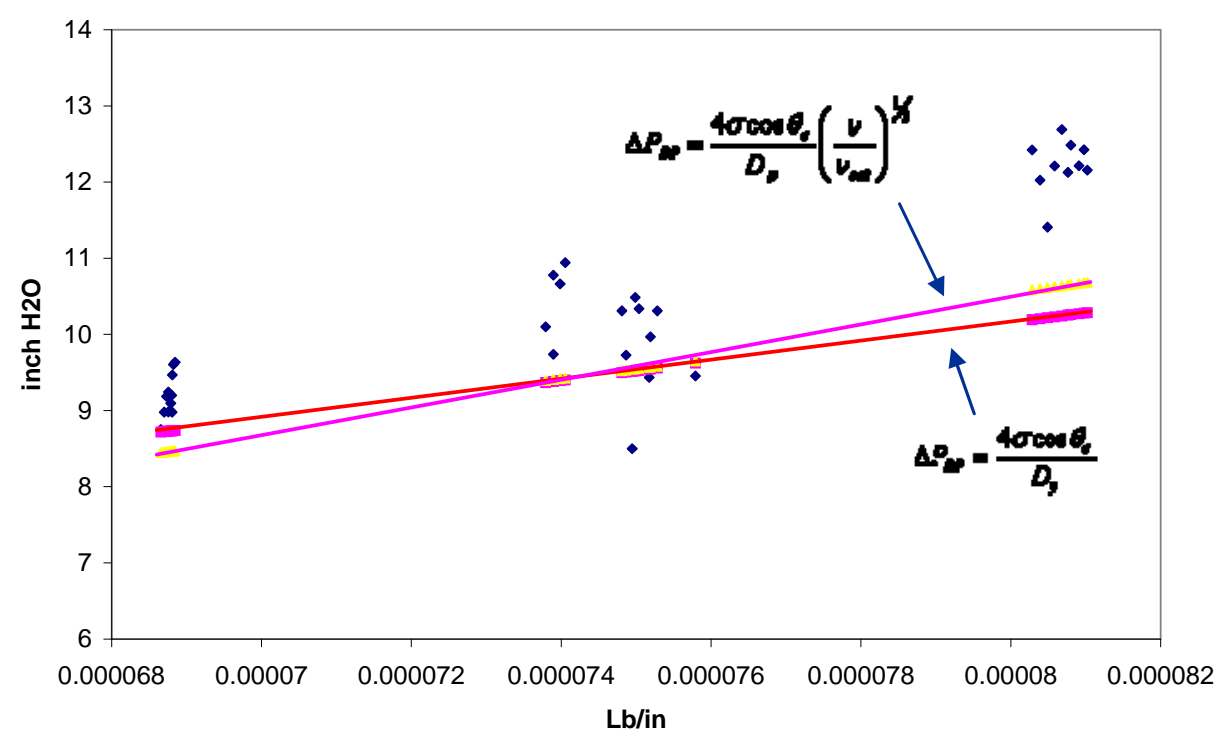

Figure 5. Bubble Point Data and Predictions for 200X1400 mesh LAD in LOX. 
three test conditions. Note that both Eq. (1) and Eq. (2) under-predict bubble point pressures at higher surface tension values (colder liquid).

Figure 6 shows test results and predictions for bubble point tests for the 325X2300 mesh LAD in LOX at the three test conditions. Note again that both Eq (1) and Eq. (2) under-predict bubble point pressures at higher surface tension values (colder liquid). It should be noted that the offset in predicted bubble point pressures at NBP may be due to an error in physical measurement of test hardware location in the test dewar.

Bubble Point vs surf tn, data \& predictions, 325X2300 LAD, LOX

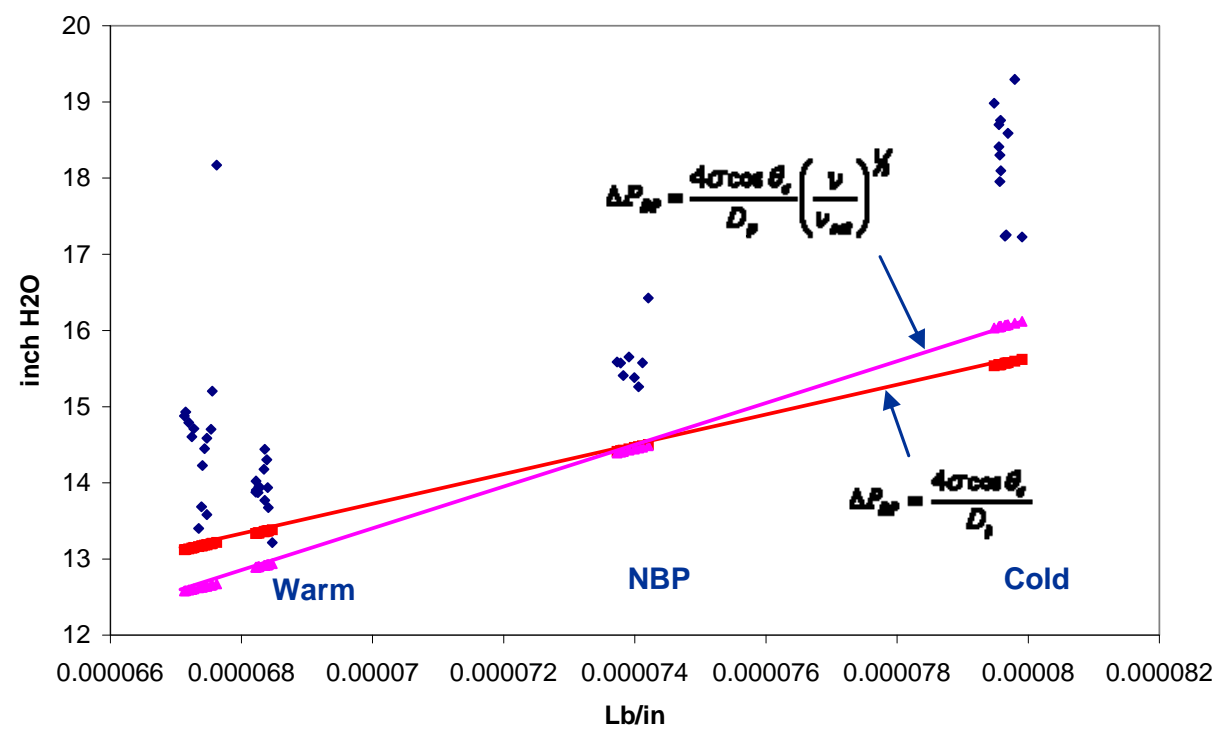

Figure 6. Bubble Point Data and Predictions for $325 X 2300$ mesh LAD in LOX

Figure 7 compiles this test data with all historical data for $\mathrm{LH}_{2}, \mathrm{LOX}, \mathrm{LN}_{2}, \mathrm{LCH} 4$, and IPA.

Bubble Point vs Surface Tension

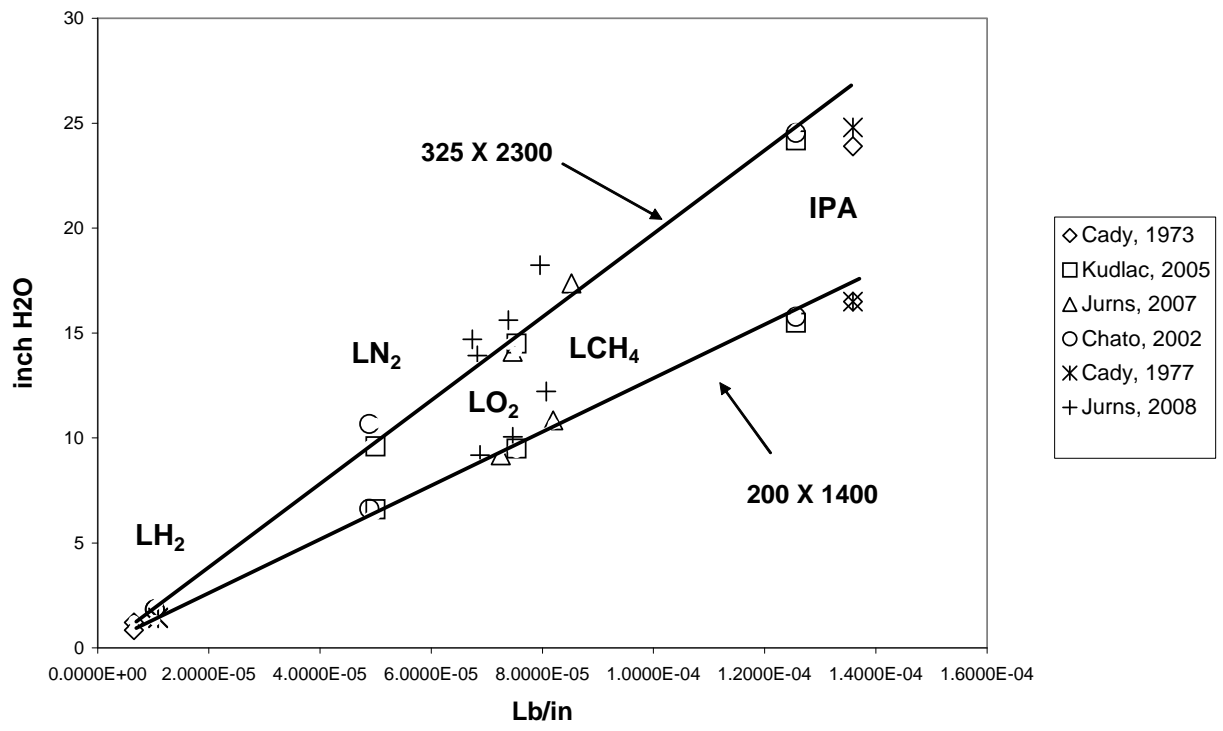

Figure 7. Summary of Historical Bubble Point Data for $\mathrm{LH}_{2}, \mathrm{LN}_{2}, \mathrm{LOX}, \mathrm{LCH}_{4}$ and IPA 


\section{Isopropyl Alcohol Tests}

In addition to LOX LAD tests, tests were performed using IPA on single orifices to examine the effect of geometry and better understand relationship between pore diameter and screen geometry. These orifices had principal dimensions that were nominally 20 microns. Three orifices were tested: A circular cross section, a square cross section, and a triangular cross section. Scanning Electron Microsocpe (SEM) photographs with measured dimensions of the orifices are shown in Figures 8, 9 and 10, respectively.

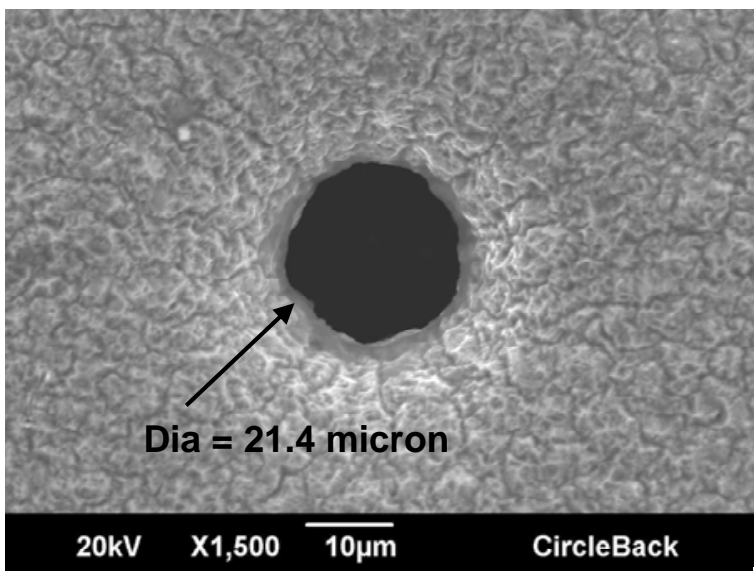

Figure 8. Nominal 20 micron round orifice

\section{Test Configuration}

The orifices were installed in a fixture as shown in Figure 11, and submersed in a container of IPA as shown in Figure 12. One side of the orifice was pressurized with $\mathrm{GHe}$ from a precision pressure controller, and the differential pressure across the orifice measured with a 0-30 inch $\mathrm{H}_{2} \mathrm{O}$ differential pressure transducer. Pressure was increased until bubbles appeared at the orifice. The pressure was then decreased until bubble formation stopped, and the test repeated several times to obtain an average bubble point pressure.

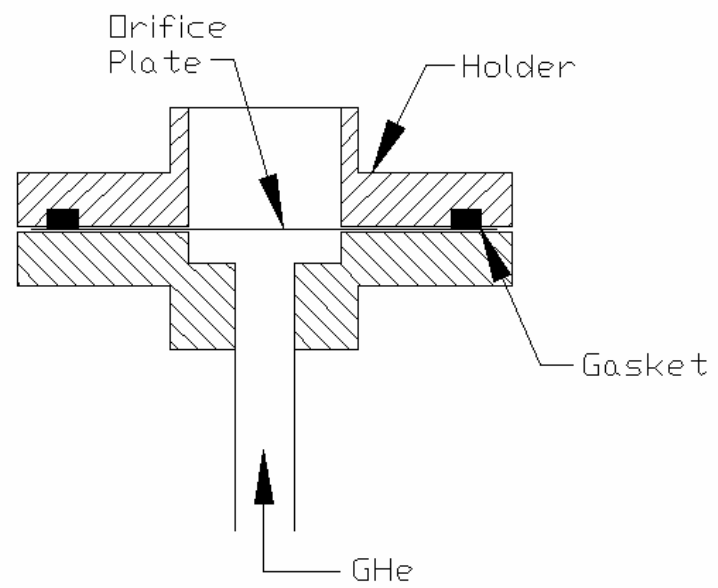

Figure 11. Detail of orifice fixture

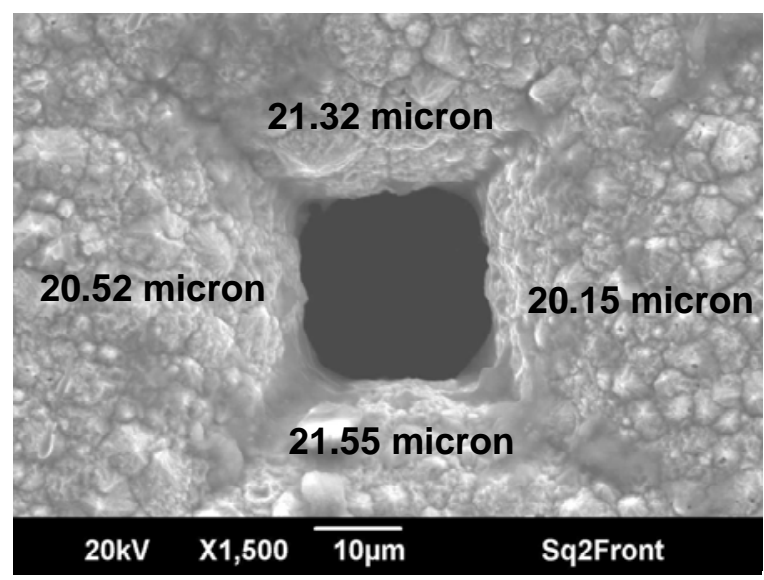

Figure 9. Nominal 20 micron square orifice

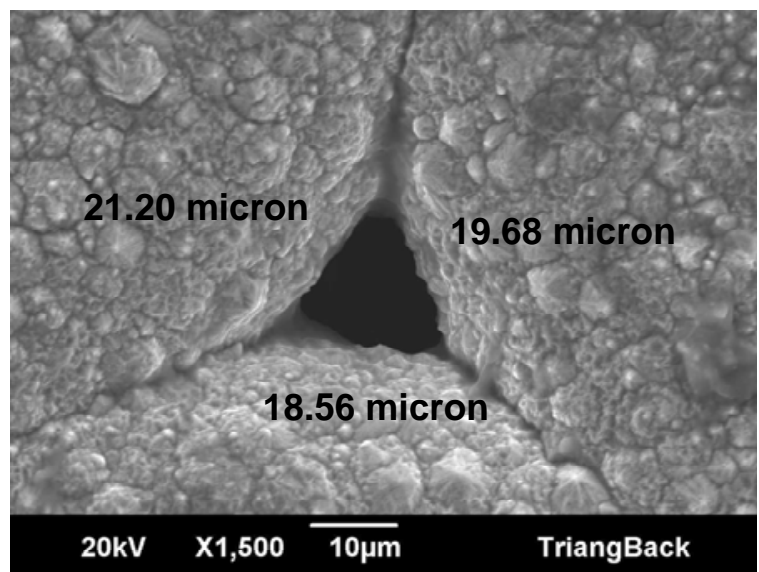

Figure 10. Nominal 20 micron triangular orifice

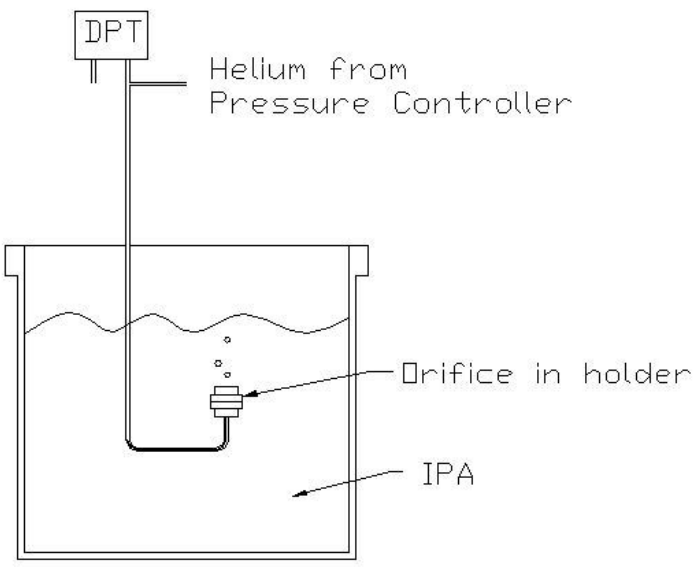

Figure 12. Orifice Bubble Point test in IPA 


\section{A. Test Results}

Bubble point pressures were measured and recorded for each orifice. Figure 13 plots measured bubble point pressure versus calculated pore diameter for each orifice.

Orifice Bubble Point vs Pore Diameter, IPA

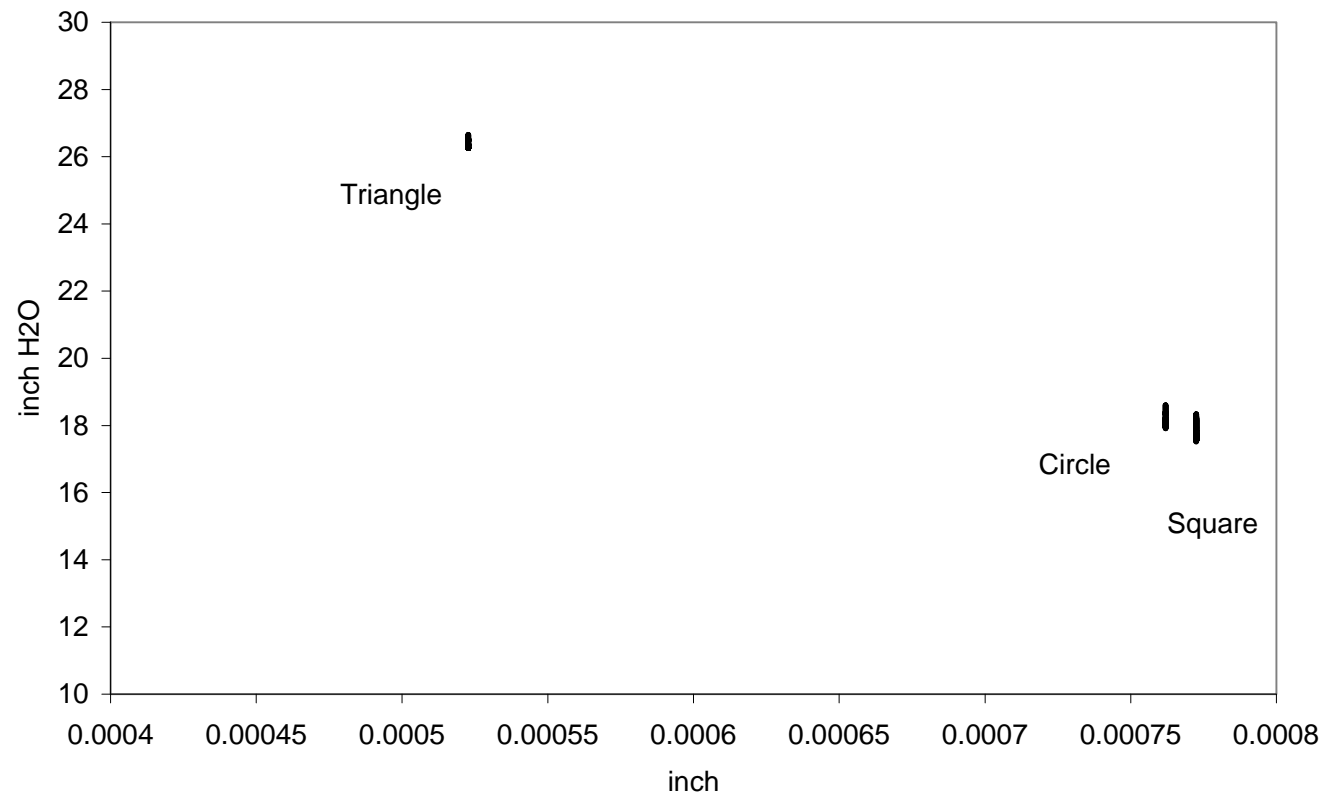

Figure 13. Measured $\Delta \mathrm{P}_{\mathrm{BP}}$ vs. pore diameter, 20 micron orifices in IPA

The calculated orifice pore diameters for measured Bubble Point Pressures are shown in Table 2.

Table 2 - IPA Bubble Point Pressure and Calculated Pore Diameter for 20 Micron Orifices

\begin{tabular}{|c|c|c|c|}
\hline Configuration & $\begin{array}{c}\text { Bubble Point Pressure } \\
\text { (inch } \mathbf{H}_{\mathbf{2}} \mathbf{O} \text { ) }\end{array}$ & $\begin{array}{c}\text { Dp calculated } \\
\text { (inch/micron) }\end{array}$ & $\begin{array}{c}\text { Dp Standard Deviation } \\
\text { (inch / micron) }\end{array}$ \\
\hline Circle & 18.10 & $0.00076 / 19.3$ & $6.2 \mathrm{E}-06 / 0.16$ \\
\hline Square & 17.85 & $0.00078 / 19.8$ & $9.1 \mathrm{E}-06 / 0.23$ \\
\hline \hline Triangle & 26.38 & $0.00052 / 13.2$ & $1.9 \mathrm{E}-06 / 0.05$ \\
\hline
\end{tabular}

\section{Discussion}

\section{A. Liquid Oxygen Tests}

Test results from this program show that Eq. (1) under-predicts bubble point pressure that increases with increased subcooling. In addition, it appears that the previously proposed kinematic viscosity term does not significantly improve predictions; therefore, other reasons must be considered for the difference between data and predictions.

The predicted bubble point pressures are based on surface tension values for saturated liquid temperature at the LAD screen. However, the liquid temperature was not measured directly at the LAD screen where the liquid/vapor interface is located. The temperature was measured using a silicon diode approximately 5 inch above the LAD screen. If the measured bubble point pressure and Eq (3) are used to calculate a surface tension value, and then determine the corresponding saturation temperature, $\mathrm{T}(\mathrm{sat})$, is 3 to $18 \mathrm{deg} \mathrm{R}$ colder than the fluid temperature measured above the screen.

$$
\sigma=\frac{\Delta P_{B P}(\text { measured }) * D_{p}}{4 \cos \theta_{c}}
$$


Since gaseous helium (GHe) is used as the pressurant gas for these tests, the partial pressure of oxygen is reduced, and, consequently, the interface temperature is reduced below the temperature of the bulk liquid. Meserole and Jones ${ }^{13}$ noted a similar effect in performing LAD tests with $\mathrm{LH}_{2}$. They noted that for tests conducted with GHe present, the bubble point pressures were equal or greater than the prediction. For this study, predicted bubble point pressures were consistently below test results, indicating the real possibility of higher surface tension values due to lower liquid temperature at the liquid/vapor interface.

Figure 14 plots surface tension versus pressure for saturated LOX. Note that the most significant change in surface tension is at low pressures, and that $\mathrm{d} \sigma / \mathrm{dp}$ decreases for higher pressures. That is, the lower the LOX temperature, the greater the change in surface tension. With colder liquid, small changes in fluid temperature could result in a greater error in predicted bubble point pressure. As these tests did not measure the fluid temperature directly at the liquid/vapor interface, and as the partial pressure of helium in the LAD test apparatus was unknown and cannot be directly measured, it is not possible to determine the exact surface tension that should be used.

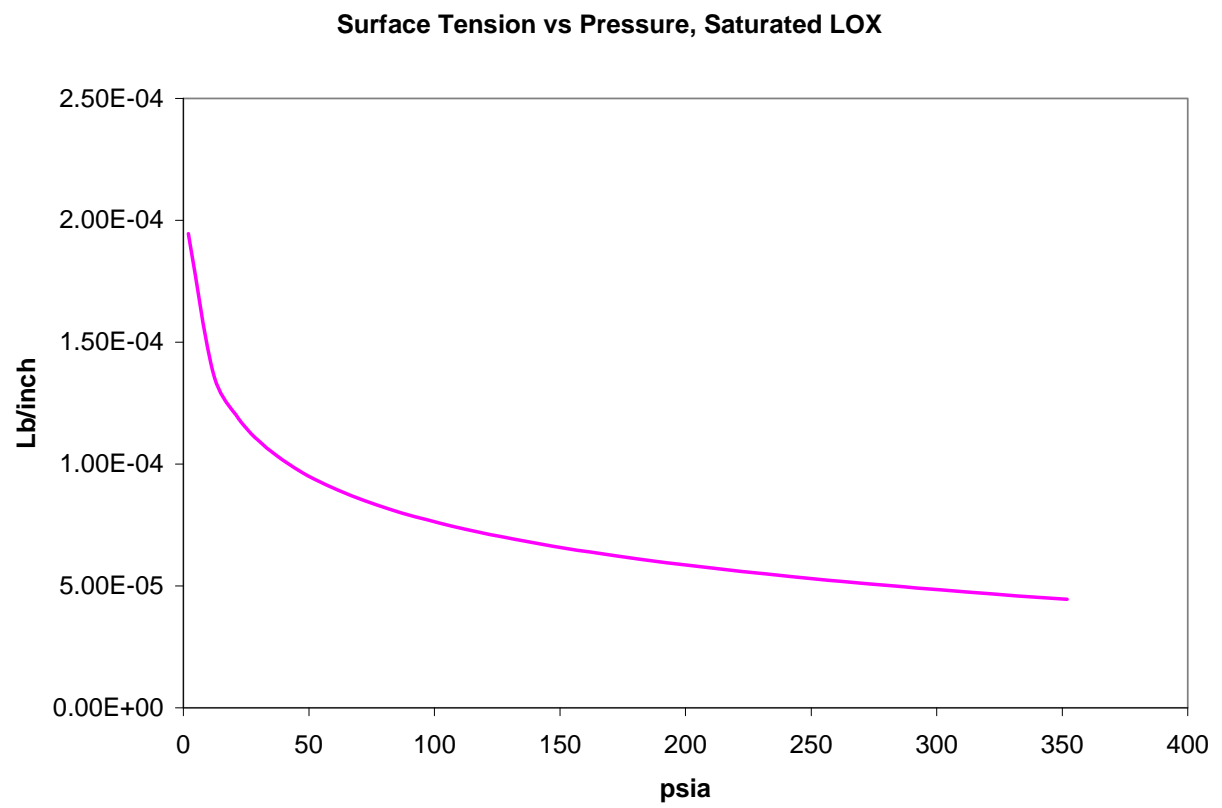

Figure 14. Surface tension vs. pressure for saturated LOX

\section{B. Isopropyl Alcohol Tests}

Pore diameters were calculated for each of the three single orifices - round, square, and triangle, using Eq. (1) and surface tension for IPA at ambient conditions. One noteworthy observation was that the breakthrough and reseal pressures for the single orifices results were nearly the same, whereas for the LAD screens, there was a hysteris effect.

The calculated pore diameter was compared to the hydraulic diameter for each orifice. also In addition, the total open area for each orifice was calculated, and from that area, an equivalent diameter for a circular orifice with the same area. Table 3 shows the results of these calculations.

Table 3 - Bubble Point Pore Diameter, Hydraulic Diameter and Equivalent Diameter for $20 \mu$ Orifices

\begin{tabular}{|c||c||c|c|c|}
\hline Configuration & $\begin{array}{c}\text { Average Principal } \\
\text { Dimension (inch) }\end{array}$ & $\begin{array}{c}\text { Dp calculated } \\
\text { (inch) }\end{array}$ & $\begin{array}{c}\text { Hydraulic Diameter } \\
\text { (inch) }\end{array}$ & $\begin{array}{c}\sqrt{(4 \mathbf{A} / \boldsymbol{\pi})} \\
\text { (inch) }\end{array}$ \\
\hline \hline Circle & 0.00084 & 0.00076 & 0.00084 & 0.00084 \\
\hline Square & 0.00082 & 0.00078 & 0.00082 & 0.00093 \\
\hline \hline Triangle & 0.00078 & 0.00052 & 0.00047 & 0.00059 \\
\hline
\end{tabular}

The hydraulic diameter is typically useful in Reynolds number calculations, and does not have much significance as a factor in comparing pore diameters to actual physical pore dimensions. The pore diameter and the "equivalent 
diameter", appear to correlate fairly well, with the pore diameter typically $10-15 \%$ lower than the equivalent diameter. This illustrates that for the same characteristic dimension, triangular openings appear to have a larger effect on the bubble point that the other geometries. An effort to correlate this to a multiple parallel openings in ongoing, similar to the situation found in a screen, but no correlation has been identified yet.

\section{Conclusions}

\section{A. LAD Screens in LOX}

Based on results from these tests, the previously proposed normalized viscosity term is not appropriate to correct for under-predicting the bubble point.. The term does not significantly improve correlation for subcooled LOX, and also under-predicts warm liquid bubble point pressures. The difference between data and predicted bubble point pressures is worse for colder LOX than for NBP and warmer liquid. With colder liquid, $\mathrm{d} \sigma / \mathrm{dP}_{\text {sat }}$ is larger, and small changes in conditions at the screen liquid/vapor interface could have larger impact on bubble point errors. If this is the case, the greatest concern for under predicting bubble point occurs with very cold liquid. As tank pressures increase, chance of under predicting bubble point should decrease.

Subcooled liquid at the screen liquid/vapor interface due to the presence of helium pressurant would increase surface tension and have a tendency to elevate bubble point. Predicting partial pressures at this interface may be difficult in real LAD systems. However, in the absence of more precise temperature measurement at the liquid/vapor interface, a limit may be imposed on the maximum predicted bubble point by using a surface tension value based on some minimum oxygen partial pressure.

\section{B. Single Orifices in IPA}

Bubble Point measurement of single orifices with different geometries revealed that there is very little difference between circular and square geometries, but a significant difference for triangular geometries. For now, it needs to be reiterated that each LAD screen should be characterized prior to use to determine its effective pore diameter. That is - pore diameters should be determined experimentally, and not assumed from a particular manufacturing specification.

\section{Future Work}

Proposed Altair (Lunar Lander) configurations will utilize gaseous helium pressurant to expel the cryogenic propellant from the tank into the engines. As such, future experimental work will collect additional bubble point data for a screen channel LAD using LOX to ascertain if the use of a pressurant gas, namely helium, has any effect on the performance. There are three proposed objectives for this test effort:

1. Ascertain whether helium dissolution into liquid oxygen is significant to alter the relevant liquid oxygen properties, namely liquid oxygen surface tension.

2. Verify liquid oxygen surface tension at "elevated" temperatures.

3. Continue the assessment of the effect of evaporation at the gas-liquid interface affects the bubble point measurement.

\section{References}

${ }^{1}$ Fester D. A. et. al. Surface Tension Propellant Acquisition System Technology for Space Shuttle Reaction Control Tanks, AIAA 75-1196, September, 1975

${ }^{2}$ Dodge F.T., "The Applicability of Surrogate Fluids for Ground Testing of Cryogenic Propellant Fluid Management Components", Final Report, Southwest Research Institute Project No. 18-11969, Feb 2006.

${ }^{3}$ Fox, J.R., McCarty, R.D., GASPAK version 3.20, CRYODATA Inc., Niwot, CO

${ }^{4}$ Sprow F.B., Prausnitz J.M., "Surface Tensions of Simple Liquids" Transactions of the Faraday Society 62, 1097 - 1104, $1966 \mathrm{~b}$

${ }^{5}$ Jurns, John $\mathrm{M}$ and Kudlac Maureen T, "NASA Glenn Research Center Creek Road Complex - Cryogenic Testing Facilities", Cryogenics 46(2006) 98-104.

${ }^{6}$ Kudlac M.T., Jurns J.M., "Screen Channel Liquid Acquisition Devices for Liquid Oxygen", $42^{\text {nd }}$ AIAA Joint Propulsion Conference, Sacramento, July 2005, AIAA-2006-5054

${ }^{7}$ Jurns J.M., McQuillen J.B., Gaby J.D., Sinacore S.A., "Bubble Point Measurements with Liquid Methane of a Screen Channel Capillary Liquid Acquisition Device", $54^{\text {th }}$ JANNAF Conference, Denver, May 2007

${ }^{8}$ Cady, E.C, "Study of Thermodynamic Vent and Screen Baffle Integration for Orbital Storage and Transfer of Liquid Hydrogen", NASA-CR-134482, August 1973

${ }^{9}$ Chato David J and Kudlac Maureen, "Screen Channel Liquid Acquisition Devices for Cryogenic Propellants", AIAA-20023983 
${ }^{10}$ Cady, E.C., "Effect of Transient Liquid Flow on Retention Characteristics of Screen Acquisition Systems", NASA-CR135218 April 1977.

${ }^{11}$ Jurns J.M., McQuillen J.B., "Bubble Point Measurements with Liquid Methane of a Screen Capillary Liquid Acquisition Device”, 2007 Cryogenic Engineering Conference, Chattanooga, July 2007

${ }^{12}$ Gauglitz, P. A., and Radke, C. J., "The Dynamics of Liquid Film Breakup in Constricted Cylindrical Capillaries," J Colloid and Interface Science, Vol. 134, p14 - 40, 1990

${ }^{13}$ Meserole, J.S., Jones, O.S., "Pressurant Effects on Cryogenic Liquid Acquisition Devices," Journal of Spacecraft and Rockets, Vol. 30, No. 2, March-April 1993 